\title{
Transcochlear Approach to a Geniculate Ganglion Hemangioma and Reanastomosis of Facial Nerve
}

\author{
Yashar Kalani $^{1}$, Sudarshan Iyer ${ }^{1}$, Manuri P. Gunawardena ${ }^{2}$, Mark Syms ${ }^{1}$, Randall Porter ${ }^{1}$ \\ 1. Division of Neurological Surgery, Barrow Neurological Institute 2. University of New South Wales
}

$\square$ Corresponding author: Yashar Kalani, stemcelldoctor@gmail.com

Disclosures can be found in Additional Information at the end of the article

\section{Abstract}

We present a case of a rare skull base tumor treated via the transcochlear approach, followed by reanastomosis of the facial nerve. After extensive skull base resection, the tumor was successfully resected and the ends of the facial nerve re-anastomosed. In an evolving era where smaller approaches are favored, there remains a place for larger skull base approaches.

Categories: Otolaryngology, Neurosurgery

Keywords: geniculate ganglion, transcochlear, facial nerve, anastomosis, hemangioma

\section{Introduction}

Geniculate ganglion (GG) hemangiomas are rare vascular lesions that frequently present with facial paresis or paralysis and/or hearing loss [1-2]. Different groups have addressed these lesions via presigmoid or middle fossa approaches [2-3]. When a hemangioma infiltrates the facial nerve, excision of the lesion can be performed with success but at the cost of losing any residual facial nerve function that may be present. Some authors have advocated reanastomosis of the facial nerve in a primary fashion or using a nerve graft $[2,4-6]$.

\section{Case Presentation}

A 53-year-old man presented to our multidisciplinary skull base team with left facial palsy. The patient was originally diagnosed with Bell's palsy and complete paralysis of his left face eight years earlier. The patient experienced some progressive improvement in facial nerve function over several years, but experienced episodes of hearing decline that resulted in imaging evaluation by his primary physician. On physical examination, there was ptosis of the left lower lid and a 5/6 House-Brackmann facial palsy with some preservation of forehead motion. An electroneuronography (ENOG) ordered as a part of the work-up revealed $4 \%$ excitability and 96\% degeneration on the left (Right: $1087.75 \mathrm{uV}$; Left: $48.07 \mathrm{uV}$ ). The patient had nonserviceable hearing on the left. Computed tomography revealed a lesion involving the left petrous bone.

(๑) Copyright 2014

Kalani et al. This is an open access article distributed under the terms of the Creative Commons Attribution License CC-BY 3.0., which permits unrestricted use, distribution, and reproduction in any medium, provided the original author and source are credited.
How to cite this article

Kalani Y, lyer S, Gunawardena M P, et al. (November 03, 2014) Transcochlear Approach to a Geniculate

Ganglion Hemangioma and Reanastomosis of Facial Nerve. Cureus 6(11): e223. DOI 10.7759/cureus.223 


\section{Cureus}

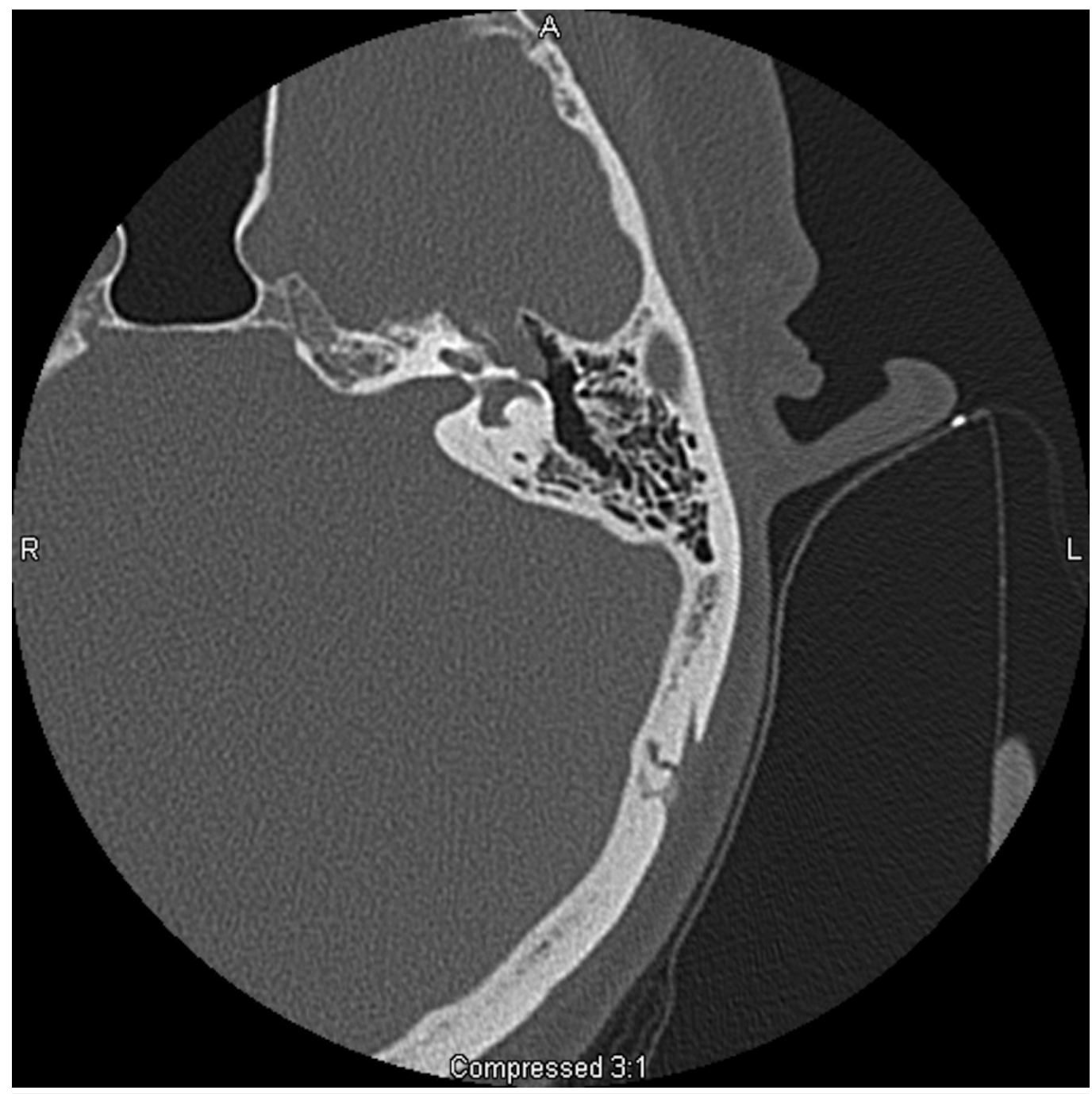

FIGURE 1: Axial computed tomography of the head reveals irregularity within the left petrous bone.

Magnetic resonance imaging revealed a heterogenous lesion involving the left facial nerve and geniculate ganglion. 


\section{Cureus}

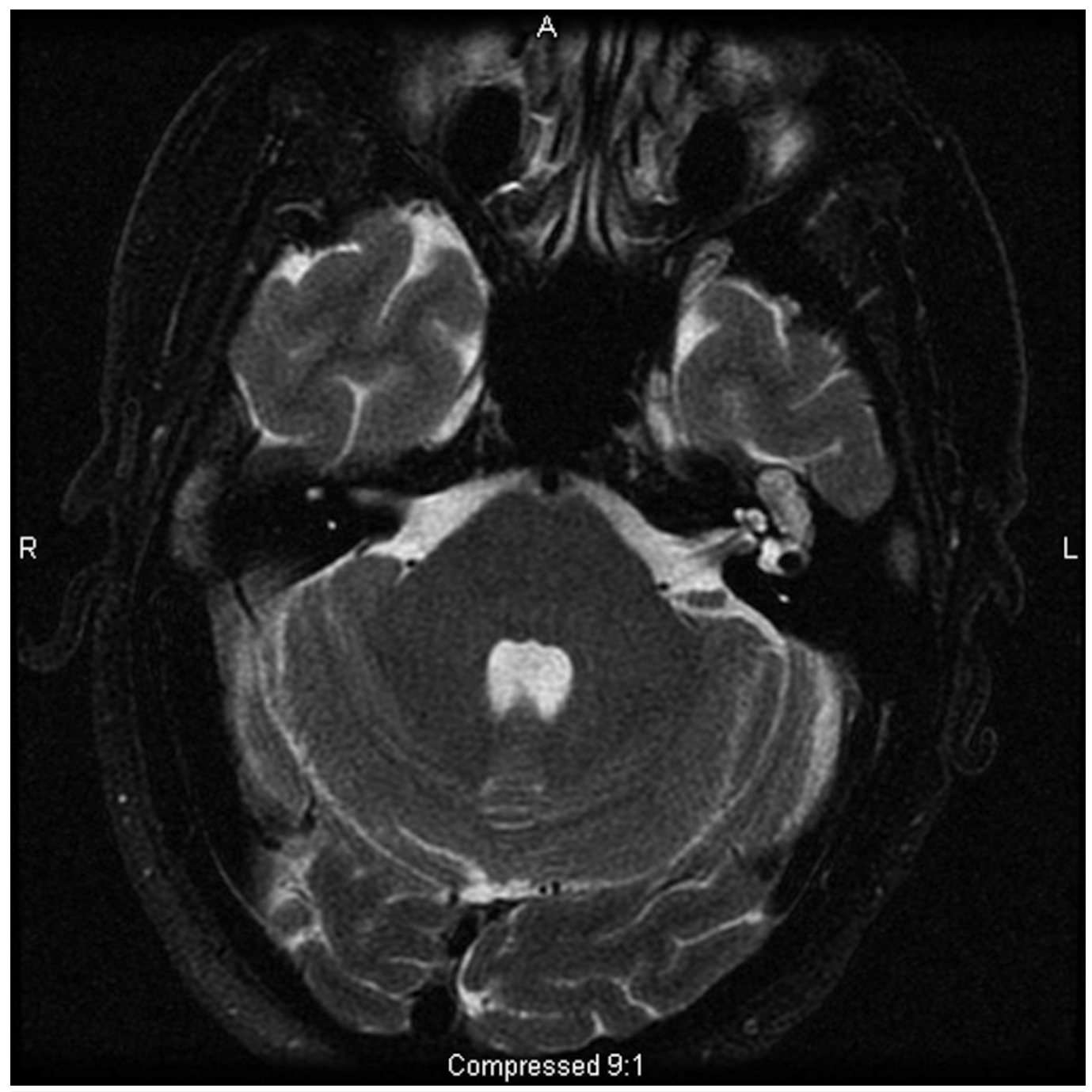

FIGURE 2: Axial T2-weighted magnetic resonance imaging reveals the lesion within the petrous bone.

After extensive discussion of the natural history and management options, including observation, radiosurgery, and skull base approach with or without anastomosis of the facial nerve, the patient elected to proceed with surgical resection of the lesion. An informed signed patient consent was obtained for his treatment.

The lesion was approached via a left transcochlear craniotomy. Although discussions of approach included the middle fossa and various presigmoid approaches, we elected to proceed with a transcochlear approach because we felt that by aggressively removing the petrous apex and otic capsule and displacing the facial nerve we would obtain the access necessary to safely remove the lesion and anastomose the facial nerve. The lesion was visualized and resected in a piece-wise fashion. The defect in the facial nerve at the GG was repaired with a single anastomosis by re-routing the nerve across the base of the geniculate triangle. The repair coupled the labyrinthine and upper horizontal segments of the facial nerve. Postoperatively the patient was neurologically at his baseline, except for worsening of the facial palsy to a $6 / 6$. His postoperative imaging revealed complete removal of the lesion. 


\section{Cureus}

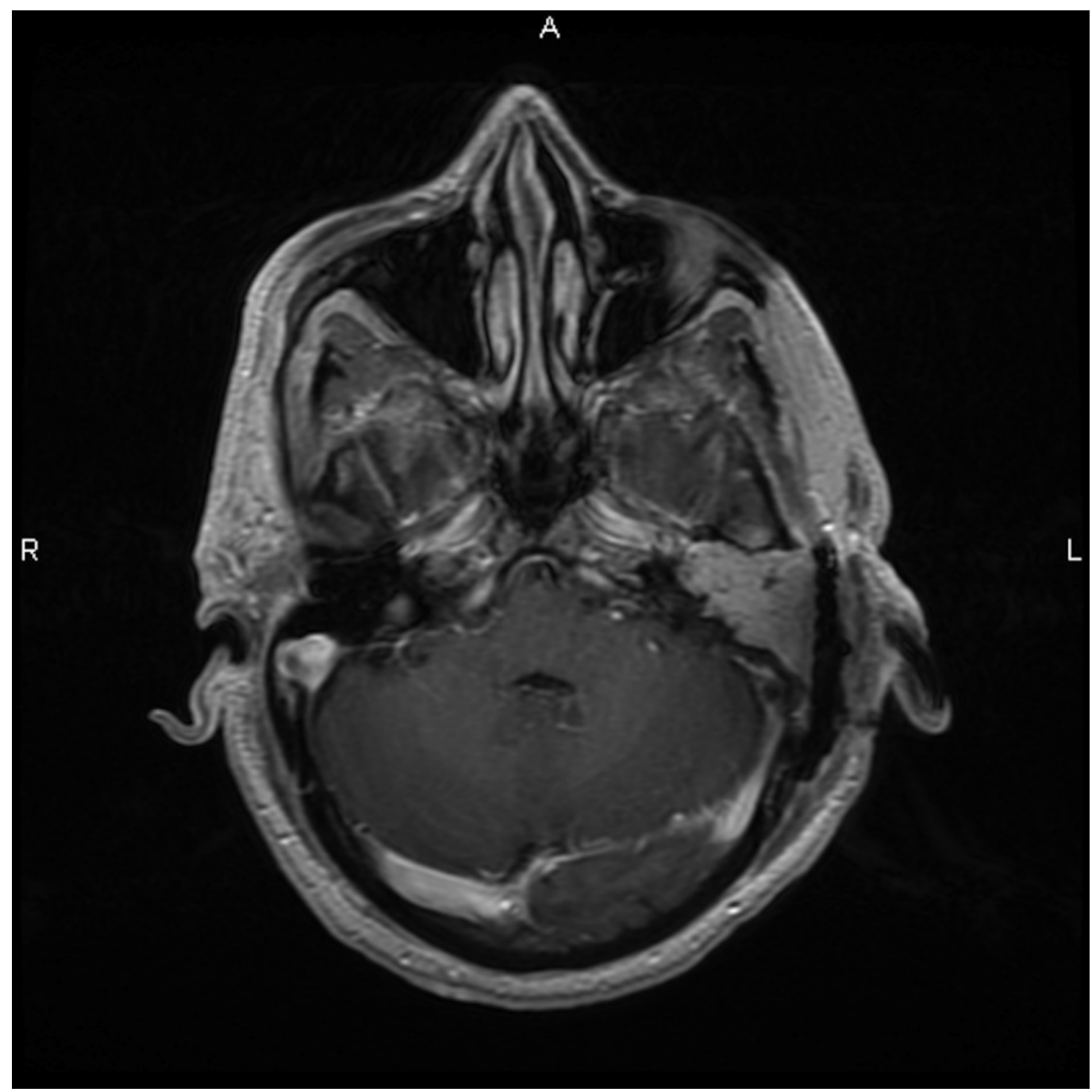

FIGURE 3: Axial T1-weighted magnetic resonance imaging with contrast post-resection demonstrates gross total resection of the lesion.

\section{Discussion}

\section{Natural history of geniculate ganglion hemangiomas}

The origin of geniculate ganglion hemangiomas is not well-defined [7]. Regardless, geniculate ganglion hemangiomas are believed to be extraneural, and more similar to vascular malformations than neoplastic tumors [2]. These lesions most likely arise from the dense capillary network in the geniculate ganglion [8-9]. Geniculate ganglion hemangiomas do not grow very fast and only sometimes will extend to other structures, such as the labyrinthine or the tympanic segments of the facial nerve [2]. When these lesions infiltrate the facial nerve, excision of not only the hemangioma but also part of the facial nerve may be necessary [5].

While geniculate ganglion (GG) hemangiomas do not grow at a fast rate, they produce significant problems at an early stage and even at small sizes $[2,10]$. The most common symptom seen with geniculate ganglion hemangiomas is some form of facial paresis or paralysis [2]. The fact that facial paresis or paralysis represents the major symptom of GG hemangiomas is significant as these lesions can sometimes be mistaken as Bell's palsy due to 
the similarities of symptoms; this originally occurred with our patient [10].

\section{Surgical options}

When managing geniculate ganglion hemangiomas, complete excision of the lesion via surgical resection is the goal. Different surgical approaches have been used to access GG hemangiomas. Two that are of note are the approach through the middle fossa and the transcochlear approach. The main advantage of the middle fossa approach lies in the good exposure of the GG and the internal auditory canal, allowing for unobstructed vision of the facial nerve without sacrifice of hearing $[2,11]$. Two major disadvantages of the middle fossa approach lie in a lack of exposure to other landmarks and the amount of manipulation that the facial nerve has to be put through over the course of the surgery. This last point serves as an explanation why the middle fossa approach does not prove as effective in retaining facial nerve function compared with other approaches [11]. The transcochlear approach allows the tumor to be operated on without risking important neurovascular structures [12]. This approach also allows for repair of the facial nerve if needed, but sacrifices hearing in the process [13].

\section{Conclusions}

Hemangiomas of the geniculate ganglion are rare vascular lesions. We report a case of a GG hemangioma treated via transcochlear approach with end-to-end facial nerve reanastomosis.

\section{Additional Information}

\section{Disclosures}

Human subjects: Consent was obtained by all participants in this study. Conflicts of interest: In compliance with the ICMJE uniform disclosure form, all authors declare the following: Payment/services info: All authors have declared that no financial support was received from any organization for the submitted work. Financial relationships: All authors have declared that they have no financial relationships at present or within the previous three years with any organizations that might have an interest in the submitted work. Other relationships: All authors have declared that there are no other relationships or activities that could appear to have influenced the submitted work.

\section{References}

1. Asaoka K, Sawamura Y, Tada M, Abe H: Hemifacial spasm caused by a hemangioma at the geniculate ganglion: Case report. Neurosurg. 1997, 41:1195-7.

2. Semaan MT, Slattery WH, Brackmann DE: Geniculate ganglion hemangiomas: Clinical results and long-term follow-up. Otol Neurotol. 2010, 31:665-70. 10.1097/MAO.0b013e3181d2f021

3. Silverstein H, Norrell H: Retrolabyrinthine surgery: A direct approach to the cerebellopontine angle. Otolaryngol Head Neck Surg. 1980, 88:462-9.

4. Falcioni M, Russo A, Taibah A, Sanna M: Facial nerve tumors. Otol Neurotol. 2003, 24:942-7.

5. Isaacson B, Telian SA, McKeever PE, Arts HA: Hemangiomas of the geniculate ganglion. Otol Neurotol. 2005, 26:796-802.

6. Miyashita T, Hoshikawa H, Kagawa M, Mori N: A case report of facial nerve hemangioma . Auris Nasus Larynx. 2007, 34:519-22.

7. Benoit MM, North PE, McKenna MJ, Mihm MC, Johnson MM, Cunningham MJ: Facial nerve hemangiomas: vascular tumors or malformations?. Otolaryngol Head Neck Surg. 2010, 142:108-14. 10.1016/j.otohns.2009.10.007

8. Balkany T, Fradis M, Jafek BW, Rucker NC: Hemangioma of the facial nerve: role of the geniculate capillary plexus. Skull Base Surg. 1991, 1:59-63.

9. Friedman O, Neff BA, Willcox TO, Kenyon LC, Sataloff RT: Temporal bone hemangiomas involving the facial nerve. Otol Neurotol. 2002, 23:760-6.

10. Shelton C, Brackmann DE, Lo WW, Carberry JN: Intratemporal facial nerve hemangiomas. 


\section{Cureus}

Otolaryngol Head Neck Surg. 1991, 104:116-21.

11. Shelton C, Brackmann DE, House WF, Hitselberger WE: Middle fossa acoustic tumor surgery: Results in 106 cases. Laryngoscope. 1989, 99:405-8.

12. House WF, Hitselberger WE: The transcochlear approach to the skull base . Arch Otolaryngol. 1976, 102:334-42.

13. Angeli SI, De la Cruz A, Hitselberger W: The transcochlear approach revisited. Otol Neurotol. 2001, 22:690-5. 